\title{
7) La historiografía argentina, los pueblos originarios y la incomodidad de los ¿ historiadores
}

Raúl J. Mandrini ${ }^{1}$

En años recientes, una polémica parece haberse instalado en ciertos Esectores de la sociedad argentina. Esa polémica, impensada hace unas décadas, se centra en la situación de los descendientes de los pueblos originarios que viven en el territorio nacional. Por un lado, crecieron y se hicieron visibles los reclamos de esos mismos pueblos tanto por reivindicaciones concretas inmediatas como por el respeto a sus costumbres, lenguas, creencias y prácticas sociales. Por otro, desde sectores muy conservadores surgieron virulentas críticas a tales reclamos que pusieron de manifiesto la persistencia de prejuicios y temores que llegaron, en algunos casos, a expresiones de exacerbada xenofobia -en especial en el caso mapuche- y un poco encubierto racismo.

Los reclamos de los pueblos originarios, respaldados por algunos sectores progresistas, crecieron en un contexto sin duda favorable. En el ámbito nacional, la apertura democrática iniciada en 1984 hizo viables esos reclamos que tuvieron alcance jurídico cuando algunas reivindicaciones fueron incluidas en la Constitución $\mathrm{N}$ acional con la reforma de 1994. Y, si bien los logros concretos fueron parciales, la visibilidad que alcanzaron esos movimientos derribó uno de los mitos fundacionales de la Nación, el de la Argentina "europea y blanca". También contribuyó un contexto internacional cuyas raíces pueden rastrearse al menos hasta la década de 1960 en el marco del avance

1 Instituto de Estudios Histórico-Sociales (IEHS), Universidad Nacional del Centro de la Provincia de Buenos Aires. El presente texto corresponde a la conferencia pronunciada el 1 de diciembre de 2006 en la Facultad de Ciencias Humanas de la Universidad Nacional de La Pampa (Santa Rosa, provincia de La Pampa), en el marco del II Encuentro de Investigadores "Fuentes y problemas de la Investigación Histórica Regional". Se añadió al texto original una nota bibliográfica. 
general en la lucha por los derechos civiles, incluidos los de los pueblos originarios, principalmente en América del Norte.

Pero más allá de las reivindicaciones puntuales, de los discursos encendidos o de la virulencia de las declaraciones $-y$, como contraparte, de las reacciones expresadas en algunas notas periodísticas y cartas de lectores- la polémica esconde un problema más profundo -una de las tantas cuestiones pendientes en la sociedad argentina-. En efecto, lo que en el fondo se discute es el lugar que los pueblos originarios deben ocupar en el contexto de la sociedad nacional global. Esto va más allá de la extensión de determinados derechos civiles, económicos, sociales o políticos pues cuestiona el carácter mismo de la sociedad nacional, pensada por sus fundadores en el siglo XIX -en consonancia con las ideas imperantes en la época- como una sociedad homogénea desde el punto de vista cultural, lingüístico y racial. Es quizá esto lo que ocasiona las reacciones más viscerales.

En esta polémica poco han dicho los historiadores, aunque algunos hayan adherido a declaraciones que, sin profundizar mucho, repudiaron las expresiones más retrógradas. Esto resulta llamativo pues, desde ambas posturas y desde distintas perspectivas, se han esgrimido argumentos que apelan a la historia como fuente de legitimación. En casi todos los casos, tales argumentos fueron sostenidos por personas que, ajenas al quehacer historiográfico, mostraron en sus argumentos un profundo desconocimiento de la producción historiográfica reciente. Pero, justo es decirlo, al gunos historiadores demostraron un desconocimiento e incomprensión no menor.

Llamativo, pero no extraño. El estudio de las sociedades originarias no fue, ni es todavía, un terreno que, en general, interese a los historiadores. Por cierto, en los últimos años algunos investigadores se han acercado al tema, especialmente jóvenes, y la producción historiográfica, virtualmente inexistente un cuarto de siglo atrás es hoy importante. Pero la temática sigue siendo ajena al grueso de los historiadores, que frecuentemente sólo se ocupan de ella de modo tangencial o, simplemente, la ignoran. Algunos incluso, al volcarse a la problemática de los pueblos originarios, abandonan su adscripción profesional como historiadores para cubrirse bajo el ambiguo rótulo de "etnohistoriadores". Y lo cierto es que las investigaciones recientes brindan elementos sólidos que invalidan la mayoría de los argumentos esgrimidos en la polémica. 
En tal situación, cabe preguntarnos qué han hecho -o no hecholos historiadores sobre estos temas y por qué. Qué hace que el tema siga generando incomodidad a muchos historiadores, y no me refiero sólo a viejos académicos aferrados a concepciones decimonónicas, sino incluso a muchos más jóvenes, excelentes profesionales que, en otros aspectos, podemos considerar progresistas. Q uizá alguna explicación a esta situación la podamos encontrar en el propio camino que siguió la historiografía argentina desde sus comienzos a fines del siglo XIX.

\section{Las perspectivas tradicionales del problema}

Si la incorporación de los territorios indígenas al Estado nacional a fines del siglo XIX significó el fin de la vida independiente de esas comunidades y su marginación económica y social -cuando no su exterminio liso y llano-, la política estatal posterior condujo a la invisibilidad de esas poblaciones en la vida nacional y también en la historia. Si en el mito de la "Argentina europea" esta era un país "sin indios", la historia de esa Argentina debía también serlo o, en todo caso, los "nativos" eran sólo cosas del pasado, reliquias arqueológicas cuyo lugar estaba en los museos de $\mathrm{H}$ istoria $\mathrm{N}$ atural creados en esos tiempos. Así, si el tema de las fronteras indias -fronteras interiores, como se las llamaba entonces- formaba parte de una heroica gesta nacional, la "lucha contra el indio", las sociedades nativas mismas quedaban borradas de esa historia. Los historiadores se desentendieron del análisis de la sociedad indígena y dejaron su estudio en manos de arqueólogos y etnólogos.

Cuál fue entonces, en concreto, la situación de ambos temas y qué carácter específico tuvieron los análisis y abordajes que se hicieron desde la historia hasta hace unas dos décadas y media. Esta reseña aunque breve me parece fundamental por dos cuestiones: por un lado, nos permite entender buena parte de las limitaciones y problemas que aún hoy enfrentamos al intentar penetrar en el tema; por otro, porque tales enfoques siguen, a veces de modo velado, vigentes en algunos medios académicos y, por supuesto, siguen sustentando las imágenes del mundo indígena vigentes en el imaginario colectivo.

Esa síntesis no resulta difícil. La historiografía argentina tradicional -asentada en el ideario romántico-liberal y en la metodología positi- 
vista decimonónica - fue dominada por una tendencia muy marcada a reducir la problemática fronteriza al tema de la "guerra de fronteras", una guerra tras la cual subyacía la oposición entre "civilización" y "barbarie" en la que esa guerra encontraba su justificación. Dicho de otro modo, la larga y costosa guerra contra las sociedades nativas se legitimaba como empresa civilizadora frente a un mundo bárbaro e irreducible.

La guerra y el conflicto fueron, sin duda, componentes importantes en la vida de la frontera, pero lo objetable es la reducción de la problemática fronteriza a la cuestión militar. La guerra, que no fue constante ni permanente, constituía en todo caso un aspecto del intrincado conjunto de relaciones que se establecieron entre ambas sociedades. Además, era manifiesta la ausencia de todo intento por comprender y explicar el funcionamiento de la sociedad indígena, del otro término de esa relación. El nativo sólo aparece como "el enemigo" y las explicaciones se redujeron a juicios de valor y a descripciones subjetivas e incluso, en muchos casos, los datos e informaciones son poco confiables.

Una visión diferente surgió en la Argentina poco después de mediados del siglo XX en algunos trabajos vinculados, especialmente, a la historia económica y social. Trabajos científicamente rigurosos, redujeron sin embargo el problema de la frontera al de la "ocupación" del territorio, concibiéndola como un espacio vacío, como una "tierra virgen". Por detrás de estos trabajos repercutían, implícitamente, ecos parciales de la vieja concepción "turneriana" de las fronteras.

Pero faltó entre los historiadores argentinos, hasta hace unas dos décadas, la consideración de la frontera concebida como algo más que un límite o separación, así como el interés por la sociedad indígena y sus relaciones con el mundo hispanocriollo. Esto último es significativo tanto porque esa sociedad ocupaba y controlaba vastas porciones del territorio como, principalmente, por los vínculos y lazos que conectaban ambas sociedades.

\section{Análisis recientes y perspectivas futuras}

Cruzando fronteras...

Quizá el aspecto más importante de los trabajos de los últimos años tenga que ver con la superación de muchos de los límites tradi- 
cionales. El primero y más importante fue aquél que había separado los campos de la antropología y la historia. U bicados en una concepción diferente de nuestra disciplina, algunos historiadores comenzamos a considerar a las sociedades originarias como un campo de estudio legítimo que nunca debimos abandonar. Al mismo tiempo, nuestro interés se abrió a una interpretación totalizadora del pasado de esas sociedades que superara la visión atomizada heredada de positivismo (y reivindicada recientemente por las corrientes neopositivistas). Así, nos acercamos a la antropología buscando conceptos e instrumentos teóricos que nos facilitaran la aproximación a nuestro campo de estudio, reivindicamos el valor de otras fuentes, como la tradición oral, la información arqueológica y los datos etnográficos, y avanzamos en una relectura de las fuentes escritas tradicionales.

En forma simultánea, algunos etnógrafos y arqueólogos abandonaron la tradición fuertemente ahistórica que dominó en gran medida el desarrollo de su disciplina para interesarse en la historia de las sociedades estudiadas buscando en ella explicaciones a los procesos socioculturales analizados. Ello implicó una revalorización de la documentación escrita, tanto en la búsqueda de explicaciones como en la formulación de hipótesis de trabajo. Esto fue particularmente importante, como veremos, en el caso de la arqueología.

La realización de proyectos conjuntos donde confluyeran historia y arqueología comenzó a dar pronto sus frutos. Así ocurrió con la investigación realizada a partir del descubrimiento, a mediados de la década de 1980, de un cementerio indígena en la localidad neuquina de Caepe Malal. El trabajo arqueológico, realizado por Adán Hajduk y Ana Biset, reveló la importancia y riqueza del sitio, ubicado cronológicamente en la segunda mitad el siglo XVIII. El trabajo arqueológico se integró muy pronto con una investigación de carácter histórico encarada por Ana Biset y G ladys Varela. La conjunción de la información arqueológica y los datos obtenidos de la documentación escrita brindó una imagen más rica de la sociedad indígena de la región en ese período y permitió la confrontación de las hipótesis obtenidas del análisis de cada tipo de información.

O tro buen ejemplo de las posibilidades de esa colaboración fueron los progresos realizados en el conocimiento de las sociedades de las Ilanuras del sur bonaerense en el siglo XVIII. En una ponencia presentada en 1986, publicada luego con algunas modificaciones, caractericé, con base en la documentación escrita, el proceso de formación en la región de un importante núcleo de economía pastoril. A 
partir de esa primera formulación, y uniendo el análisis de fuentes y su experiencia de campo, algunos arqueólogos establecieron para las regiones serranas de Tandilia y de Ventania, al menos a mediados del siglo XVIII, el uso por parte de los indígenas de técnicas destinadas a la concentración, custodia y engorde de los ganados que incluían el uso de potreros en mesetas y valles interserranos y la realización de construcciones de piedra, incluidos corrales, destinadas a hacer esos sitios más segu ros y fáciles de vigilar. Tales construcciones -que formaron parte de un sistema mucho más extenso- sirvieron como infraestructura de apoyo para las grandes recogidas de ganado en pie para ser llevado, a través de las pampas, hasta tierras trasandinas. La interpretación de estos hallazgos -considerados en su conjunto- como parte de un vasto sistema vinculado a la actividad pastoril y al comercio de ganados -aspectos ampliamente documentados en las fuentes escritas- resultó perfectamente congruente.

M ás recientes, merecen citarse los trabajos arqueológicos realizados en el antiguo territorio ranquel en la actual provincia de La Pampa 0 , desde perspectivas distintas, algunas investigaciones de carácter arqueológico en antiguos fortines de la campaña bonaerense del siglo XIX. Estos segundos trabajos, que se definen a sí mismo como "arqueología histórica", término bastante cuestionable, presentan todavía debilidades considerables, en gran parte por la falta de articulación con investigaciones de carácter histórico. Aquí, la importante documentación de archivo disponible podría enriquecer las investigaciones, dándoles una proyección y profundidad de la que actualmente carecen.

Pero, aunque el avance fue grande, no debemos engañarnos. Más allá de la aceptada interdisciplinariedad -en muchos casos sólo declamada- son en realidad pocos los proyectos conjuntos encarados por historiadores y arqueólogos. Los historiadores rara vez integran a sus trabajos información arqueológica; los arqueólogos, a su vez, suelen ignorar los avances de la historiografía y algunos se han puesto a "hacer historia" con resultados decepcionantes. Sin embargo, cuando los arqueólogos comienzan a leer la documentación escrita con ojos de arqueólogo los resultados suelen abrirnos a los historiadores campos impensados. En este aspecto el camino futuro deberá pasar por la elaboración de proyectos conjuntos de largo alcance.

Un segundo aspecto de esta ruptura de las fronteras establecidas tuvo que ver, para los historiadores, con salir de los límites impuestos 
por una historiografía de tipo nacional o, más correctamente, nacionalista que, nacida al calor de los procesos constitutivos del Estadonación en la segunda mitad del siglo XIX, encuadró en los límites de esa "nación" -físicos, políticos y culturales- toda la historia anterior, incluía la de los pueblos originarios. Resultó y resulta frecuente leer o escuchar hablar de "indios argentinos", "indios chilenos", "indios bolivianos", etc., esto es, definidos a partir de su ubicación en el territorio de cada nación. Así, la cordillera andina se interpuso como un límite infranqueable entre las poblaciones de la Araucanía y de las pampas, generando en ambos Estados visiones distintas y a veces antagónicas de los grupos sometidos, tal como lo expuso muy claramente Martha Bechis, hace ya años, en su tesis doctoral.

Pero aprendimos -tanto en Argentina como en Chile- que era imposible entender a las pampas sin la Araucanía, o a la Araucanía sin las pampas, como lo reflejan los trabajos de investigadores de ambos países: Leonardo León Solís y Jorge Pinto Rodríguez, entre otros, en Chile; Miguel Ángel Palermo, Daniel Villar y Juan Francisco Jiménez, además de M artha Bechis, en Argentina. Al hacerlo, la cordillera dejó de ser el muro o la barrera que separaba esos mundos para convertirse en un espacio que los articulaba. $Y$, sin perder de vista las especificidades de cada región de ese vasto espacio, comenzamos a pensar en una historia común, de pueblos indisolublemente unidos, más allá de los periódicos ciclos de conflicto.

Pero tampoco en esto debemos engañarnos. Fuera de algunos ámbitos reducidos, debo reconocer que buena parte de mis colegas siguen pensando los espacios en términos de Estados nacionales, pensando esa historia en término de chilenos o argentinos, y aún para etapas en que la Argentina no existía como realidad política. Y, para ser consecuentes, cuando miramos hacia adentro del territorio -probablemente por comodidad-seguimos a menudo pensando en términos de territorios provinciales, aún para períodos en que esas provincias no tenían siquiera una existencia ideal. Por contraposición, seguimos teniendo poco claro los distintos espacios que conformaron el territorio de los pueblos originarios -sea en el aspecto geográfico, en el económico o en el político- así como la forma en que esos espacios se vincularon y articularon en unidades mayores y más abarcativas.

¿Cómo pensar y definir entonces los espacios ocupados por la población aborigen? La tarea no es fácil, porque habrá que tener en cuenta distintos aspectos. En primer lugar, los temporales. Así, tomar 
como referencia las grandes unidades políticas -cacicatos- puede ser un criterio útil para las décadas centrales del siglo XIX (en algún caso un poco más), pero la creación de esas unidades es un fenómeno típico de esa etapa y resulta bastante cuestionable proyectarlos mucho más hacia atrás. En segundo lugar, la alta movilidad -por distintos motivos- de esas poblaciones. En tercer término, la fuerte integración alcanzada por ese territorio hacia mediados del siglo XIX -tanto cultural y lingüística como económica- que tiende a ocultar diferencias y crear la imagen de una uniformidad que, sin embargo, nunca terminó de borrar las diferencias.

De todos modos, las características geoecológicas del territorio -claramente percibidas por los pueblos nativos-, permiten definir ámbitos y áreas con funciones económicas precisas que articulaban actividades diferenciadas, impulsaban el desarrollo de distintos modelos económicos, definían las líneas centrales de la circulación y condicionaban la distribución de la población y su movilidad. Este complejo de rasgos, sobre el cual se modelaron las grandes unidades políticas del siglo XIX, explica también muchos de los conflictos internos y contribuye a definir las políticas nativas frente a la sociedad hispanocrioIla. Es en estas definiciones donde, pienso, debemos poner mucho de nuestro esfuerzo en las próximas etapas de trabajo.

De igual modo, otra cuestión pendiente, no menos compleja, es la temporal, específicamente, la de la periodización a adoptar en la construcción de esa historia indígena. Pareciera obvio que hablar de período colonial, virreinal, republicano o independiente (más allá de su comodidad cronológica) tiene poco sentido y no nos dice nada acerca de los procesos, cambios, continuidades y rupturas que se operaron en ese mundo indígena. ¿Q ué puede significar para este mundo fechas como 1776, 1810, 1816, ó 1853, por dar algunos ejemplos? Por supuesto, que lo que ocurría en el mundo hispanocriollo tenía importancia para el mundo indígena dadas las vinculaciones y la interdependencia entre ambas sociedades. Pensemos sólo en el impacto que tuvo el triunfo del proyecto liberal en la década de 1860, que acabó con la destrucción de ese mundo y su anexión definitiva al Estado nación.

Pero esto no debe ocultar la importancia de la dinámica propia de los procesos que se operaron en el mundo indígena y la participación y el rol que le cupo a la sociedad nativa en la definición del carácter y el ritmo de los cambios que se fueron operando. No fue un receptor 
pasivo de políticas e iniciativas que emanaban de la sociedad blanca sino que fue capaz de elaborar repuestas y generar sus propias acciones. Incluso conocemos, cada vez con más claridad, algunos procesos que se desarrollaron dentro de la sociedad indígena y que difícilmente puedan explicarse sólo por referencias a acciones del ámbito hispanocriollo. Pienso, específicamente en el caso de los conflictos internos y los largos ciclos de guerras intergrupales, cuya importancia fue más grande de lo que pensábamos y que tuvieron un impacto profundo sobre muchos aspectos de la vida aborigen, como lo han mostrado los trabajos recientes de Daniel Villar y Juan Francisco Jiménez. Cómo podemos entonces ignorar el desarrollo de tales conflictos al periodizar la historia indígena.

Cuestionar y cuestionar, he ahí la clave...

O tro aspecto significativo de los trabajos emprendidos fue la revisión y el cuestionamiento de conceptos y categorías tradicionalmente utilizados en el área. El caso más significativo es el que se refiere a la utilización del concepto de "complejo ecuestre [horse complex]" que había sido clave en la interpretación tradicional del proceso cultural operado en las pampas a partir del siglo XVI. En este caso, la revisión de las fuentes y la obtención de nuevas informaciones sobre el carácter de la economía indígena, permitieron a Miguel Ángel Palermo demostrar lo inconveniente de seguir utilizando tal concepto dado que las realidades sociales a las que se aplicaba eran radicalmente distintas a aquéllas para las cuales había sido elaborado.

También se cuestionó el concepto de "araucanización", o al menos su uso por los etnólogos difusionistas. Más allá de la legitimidad del término mismo, resulta hoy claro que esa "araucanización" constituyó un proceso largo y complejo que incluyó tanto la incorporación de un amplio espectro de elementos culturales originarios de la Araucanía por las poblaciones pampeanas, especialmente a lo largo del siglo XVIII, como el asentamiento en la región de grupos provenientes de aquella zona, en particular desde el comienzo de la tercera década del siglo XIX. Con Sara O rtelli trabajamos el tema, avanzando en una descripción y periodización del proceso así como en la explicación de las causas que facilitaron la rápida aceptación de esos elementos por las poblaciones locales. Tal aceptación, especialmente de elementos de alto valor simbólico, debe relacionarse, por fuerza, con las transfor- 
maciones económicas y sociopolíticas evidentes en las pampas a partir de mediados del siglo XVIII, cuyas poblaciones no fueron receptoras pasivas de las innovaciones culturales sino partícipes y actoras de los procesos de cambio vividos.

Sin embargo, no se ha realizado aún una crítica sistemática a otros conceptos, como el de "tehuelchización", profusamente utilizado por Casamiquela, y siguen aún pendientes de un análisis más profundo cuestiones vinculadas con las definiciones mismas de "etnia" y "etnicidad", con el reconocimiento de los distintos grupos étnicos en la región y de los procesos de etnogénesis que se produjeron. El problema de la clasificación étnica parece resultar aún más difícil de resolver. Las discusiones se centraron esencialmente en torno a las clasificaciones realizadas por los misioneros de mediados del siglo XVIII -la época de las clasificaciones- signada por las figuras de Linneo y Lamarck. Este vuelco a las taxonomías implicaba un intento de los estudiosos por poner orden en el mundo natural y social que los rodeaba. Tal fue lo que intentaron hacer los misioneros, especialmente los jesuitas, en distintas partes del continente con el confuso mosaico étnico que presentaban las poblaciones amerindias.

Para ellos, la cuestión parecía clara. Cómo captar, entender y describir un mundo en transformación y en continua movilidad. Cómo conocerlo sin imponer en él un orden, una sistematización. Conocer ese mundo y esas realidades implicaba pues describirlo y ordenarlo, determinar cuáles eran sus componentes -naturales y humanos-y las relaciones entre ellos, fijarlos en el espacio y en el tiempo. En esta tarea intelectual las taxonomías constituían, para la época, una herramienta epistemológica fundamental. Al clasificar, se podía "ordenar" la realidad, comprenderla y aprehenderla; en suma, apropiarse de ella. Los viejos etnólogos, empero, tomaron esas clasificaciones como si fueran reflejos de la realidad misma, descalificando a algunos misioneros y exaltando a otros, según se acomodaran a sus propias concepciones.

En general, la terminología utilizada por las fuentes es confusa y se mezclan a menudo los criterios dando lugar a una multiplicidad de nombres y apelativos que en muchos casos se refieren a pequeñas parcialidades $y$, en otros, a extensos grupos étnicos. Un mismo término puede designar a distintos grupos 0 , por el contrario, se aplican al mismo distintos nombres. U na gran parte de los nombres sólo tienen significado espacial o designan la posición de un grupo respecto a otros: así, se puede ser huilliche para quienes están situados más al norte o picunche para los que viven al sur. 
Pero las etnias no son meras "etiquetas" aplicadas a distintos grupos humanos ni las identidades étnicas esencias inmutables. Son realidades históricas, la etnicidad se construye históricamente y las identidades se definen históricamente en un complejo proceso de relación con los otros. Estos puntos simples deberían ser el punto de partida para reconstruir los procesos de etnogénesis en la región, algo aún por hacerse, pese a algún intento en ese sentido como el de Lidia Nacuzzi, lamentablemente muy acotado en tiempo y espacio. La reciente tesis doctoral de Julio Vezub avanzó en este sentido para el caso de los "manzaneros" durante las décadas centrales del siglo XIX. Aquí, las propuestas de Guillaume Boccara, así como algunos trabajos realizados en los Estados U nidos, constituyen un punto de partida interesante para futuras discusiones.

No menos importante resultó la reformulación del concepto de "frontera". A diferencia de las concepciones anteriores, elaboradas a partir de la experiencia de los Estados nacionales modernos que confundían frontera con límite, comenzamos a pensar la frontera como un vasto espacio social en el que se desarrollaron procesos históricos específicos que debíamos intentar desentrañar y en los cuales las múltiples y complejas relaciones entre ambas sociedades ocuparon un lugar central.

En esta dirección apuntaban los trabajos pioneros de Kristine Jones y de Martha Bechis y fue la que seguimos quienes tomamos ese camino. Sin embargo, en la Argentina, la historia de las fronteras así entendidas está aún por hacerse, aunque tengamos hoy trabajos puntuales significativos entre los que deben destacarse los de Silvia Ratto y de Daniel Villar y Juan Francisco Jiménez para la frontera de Buenos Aires en la primera mitad del siglo XIX, que ponen de relieve la diversidad y la intensidad de las relaciones entre ambas sociedades.

\section{La nueva caracterización de la sociedad indígena}

Resultado de esas rupturas y cuestionamientos, de la formulación de nuevos problemas y preguntas, de la búsqueda de nuevas fuentes o de caminos diferentes para abordar las ya conocidas, en no mucho tiempo comenzó a cambiar nuestra visión del mundo indígena y la caracterización que de él teníamos. La historiografía tradicional había consolidado en la Argentina una visión particular del mundo indígena que cuajó en la expresión "el desierto" y que tuvo particular éxito 
hasta hace apenas pocos años. Pero tal descripción tenía poco que ver con las realidades etnográficas a las que supuestamente se referían.

En efecto, una lectura crítica de la documentación conservada muestra, más allá cualquier duda, que tanto en el aspecto geográfico 0 en el humano, ese territorio distaba mucho de ser un desierto. Ante todo, la región, que se caracterizaba por una variedad de paisajes y ámbitos ecológicos que no pasó desapercibida a quienes la recorrieron, no era precisamente una vasta y monótona llanura abierta y plana. Además, ese extenso territorio constituyó el hábitat de una importante población indígena; su número, imposible de estimar con precisión, debió alcanzar a mediados del siglo pasado a muchos miles de personas con capacidad para poner en batalla ejércitos de centenares de lanceros.

Un aspecto significativo del trabajo realizado fue la reformulación y redefinición de las bases materiales de esa sociedad india. El análisis de la economía indígena puso de manifiesto su complejidad y obligó a abandonar viejas ideas, generalmente basadas en prejuicios y preconceptos, dejando de lado definitivamente la calificación de "depredatoria" que se le había adjudicado. Por el contrario, abarcaba un amplio espectro de actividades (pastoreo en diversas escalas, caza, agricultura, recolección, producción artesanal) combinables en diferentes grados y formas lo que le otorgaba una excepcional adaptabilidad.

Un complejo sistema de intercambios vinculaba a las distintas unidades del mundo indígena y a éste con la sociedad criolla. Este circuito, conformado sobre antiguas vías de contacto prehispánicas, estaba ya en funcionamiento pleno hacia mediados del siglo XVIII y se consolidó en el siguiente. Vinculados al desarrollo de esos circuitos, pudimos entonces avanzar en la caracterización de algunos procesos regionales, especial mente para la segunda mitad del siglo XVIII, cuando el desarrollo de esos circuitos de intercambio a larga distancia generó importantes procesos de especialización económica en la región. A partir de allí pudimos avanzar en el análisis de las estructuras y del funcionamiento de esa economía, de sus articulaciones, de las variaciones regionales, de las transformaciones que se produjeron en el tiempo.

Otra idea arraigada que debió abandonarse es la del "nomadismo" de los indígenas pampeanos, quienes estaban asentados en parajes bien determinados donde la presencia de pastos, agua y leña hacía posible su supervivencia; algunos lugares, como las tierras vecinas a las 
sierras del sur bonaerense, los valles del oriente pampeano, el monte de caldén y los valles cordilleranos, fueron centros de asentamiento de importantes núcleos de población. La alta movilidad de los indígenas, determinada por la circulación de los ganados, las actividades mercantiles, o la participación en parlamentos, asambleas o rituales colectivos, no debe confundirse con nomadismo (Nacuzzi 1991; 1998). En algunos casos, como el sur bonaerense o la zona cordillerana, puede hablarse a lo sumo de un seminomadismo estacional determinado por las necesidades de mover los rebaños de los campos de verano a los de invernada.

También sabemos hoy que las estructuras sociales y políticas del mundo indígena eran muy complejas. Procesos de diferenciación social y acumulación de riqueza, formación de grandes unidades políticas (cacicatos) y concentración de autoridad en los grandes caciques (Callfucura, Mariano Rosas o Sayhueque, por ejemplo), se operaron entre los siglos XVIII y XIX. Algunos aspectos de este desarrollo no son aún bien conocidos, pero el proceso es, en líneas generales, indiscutible.

En ese contexto, hemos avanzado en la comprensión de los procesos políticos. Algunas investigaciones -como las de Villar y Jiménez ya citadas- han puesto de relieve la existencia de ciclos de violencia intraétnica, determinando su estructura, describiendo su desarrollo, definiendo su cronología y analizando los efectos que tuvieron sobre la vida de las comunidades involucradas. O tros, como la reciente tesis de Vezub sobre Sayhueque, permiten empezar a entrever el funcionamiento interno de las grandes unidades políticas.

Este reconocimiento, incompleto aún, de las realidades geográfica y etnográfica, constituye un paso fundamental para separar y distinguir de ellas a los componentes ideológicos que participaron en la construcción de las imágenes que se forjaron del mundo indígena y su territorio, imágenes estrechamente ligadas al proceso histórico de constitución del Estado nacional. Pero queda mucho por hacer y a lo largo de la exposición hemos ido señalando los límites de los avances realizados. Además, pese a algunas coincidencias básicas, las diferencias entre los estudiosos en torno a cuestiones centrales siguen siendo grandes.

Hay, en efecto, coincidencia en considerar a la sociedad indígena mucho más compleja en su funcionamiento y en sus estructuras de lo que historiadores y etnólogos habían supuesto durante muchos años. También hay acuerdo sobre la imposibilidad de entenderla sin atender 
a sus relaciones -múltiples y no menos complejas- con la Araucanía y con la sociedad hispanocriolla. Por último, parece fuera de discusión que ese mundo indígena sufrió cambios y transformaciones a lo largo del período.

Sin embargo, las divergencias aparecen al evaluar el alcance y el carácter de tales cambios así como su cronología. Sin duda, parte de ellos están directamente ligados a los contactos con la sociedad hispanocriolla y con los pueblos de la Araucanía, pero en lo esencial parece -o mejor, nos parece a algunos- que tales cambios resultan de un dinámica más compleja en la cual las trasformaciones internas de la sociedad indígena, frente a las nuevas condiciones históricas de su existencia, fueron tanto o más importantes que las influencias o contactos externos. Así, la rápida incorporación de elementos alóctonos fue posible, en realidad, gracias a esas transformaciones, y más que una "causa" de las mismas, tal incorporación habría contribuido a reforzar los cambios producidos. De hecho, por ejemplo, la incorporación de bienes culturales transandinos precedió al ingreso y asentamiento masivo de grupos de ese origen, fenómeno que recién se verificó en las primeras décadas del siglo XIX.

Menor aún parece ser el acuerdo a la hora de caracterizar a la sociedad indígena, especialmente en lo que hace al carácter de las estructuras sociopolíticas de las formaciones sociales pampeano-patagónicas, y los investigadores no han conseguido ponerse de acuerdo en su definición. Todas las formas usualmente reconocidas en las tipologías de los sistemas políticos preestatales han sido empleadas (banda, tribu, confederaciones tribales, cacicato o jefatura) y no siempre a partir de definiciones claras, y lo mismo pasa en la caracterización de las diferencias sociales internas (sociedades igualitarias, de rango, jerárquicas, estratificadas).

Personalmente, entiendo que la categoría de "jefatura" es la que más se ajusta a la información histórica disponible, y es por tal motivo que una hipótesis central de mi investigación fue la definición de los grandes cacicatos indios -al menos hacia mediados del siglo XIXcomo verdaderas "jefaturas" (chiefdoms), traducción que prefiero a la de "señorío", que tiene otras connotaciones, y en ese sentido he tratado de definir sus rasgos a partir de las formulaciones existentes pero, fundamentalmente, de seguir el proceso histórico de conformación de esas jefaturas, proceso más largo y complejo de lo que podíamos suponer al empezar nuestro trabajo. 
El gran vacío: después del "wingka aucan"

Finalmente, un gran vacío en la investigación es el que corresponde al período posterior a la incorporación de los territorios indígenas del sur al Estado nacional argentino. La ocupación de esos territorios, conocida en la historia argentina como "conquista del desierto" -el wingka aucan, para los indígenas-, ocupaba un lugar importante en el proyecto económico y político de la elite criolla y de los sectores dirigentes argentinos. Pero la conquista, como todas las conquistas, tuvo su lado oscuro, el de los vencidos. ¿Cuál fue, en efecto, su destino? Muchos indios murieron en combates o en la huida; otros, principalmente mujeres, niños y ancianos, fueron capturados por las fuerzas expedicionarias. Algunos lograron cruzar la cordillera para unirse a sus hermanos de Chile en espera de la ocasión propicia para retornar a sus tierras.

Más triste fue el destino de los capturados: hacinados en campos de prisioneros, durmiendo al aire libre, sin abrigo ni alimento suficiente -apenas lo había para los soldados-, fueron víctimas indefensas del frío, el hambre y las enfermedades. Pocos sobrevi vieron: las mujeres y los niños para terminar como sirvientes en las casas de las familias más ricas de las elites urbanas; los hombres para caer víctimas del trabajo forzado en los barcos o la zafra azucarera. Aún aquellos grupos que mediante tratados con el gobierno habían recibido tierras para asentarse fueron sometidos, por presiones económicas y políticas o por argucias legales, a un paulatino pero continuo despojo.

Marginadas económica y socialmente e invisibilizadas por la política del Estado, las comunidades aborígenes no desaparecieron. Algunos grupos sobrevivieron y se acomodaron a la nueva situación; otros, retornaron poco después de las tierras trasandinas donde habían buscado refugio cuando esos territorios fueron incorporados, apenas un par de años después, por el Estado chileno. Las comunidades comenzaron así una larga lucha por la supervivencia que aún continúa. En ese proceso de un siglo, los pobladores nativos debieron cambiar -al menos para afuera, es decir, para el "blanco"- muchas de sus prácticas y costumbres y reformular sus identidades. $Y$ lo hicieron exitosamente como lo demuestra su supervivencia en las peores condiciones.

Es justamente este rico proceso de cambios, ajustes y transformaciones el que quedó olvidado por los historiadores. Algunas formulaciones más o menos románticas, sin fundamentos en la investigación empírica, han querido ver en el resurgimiento reciente de los pueblos 
originarios -o mejor dicho, en la nueva visibilidad por ellos adquiri$\mathrm{da}-$, un renacimiento de las antiguas comunidades que habrían continuado ocultas por el proceso de invisibilización impuesto desde el Estado nacional. Nada parece más falso, y los poquísimos trabajos empíricos encarados nos muestran la complejidad de los procesos que tuvieron lugar y la multiplicidad de caminos seguidos durante ese largo siglo de sometimiento.

El caso tal vez más estudiado es el de la comunidad agropastoril aborigen de Cushamen, en el noroeste de la actual provincia de Chubut. Establecida por linajes provenientes del centro neuquino y las tierras vecinas de la Araucanía, pudieron negociar su establecimiento y la entrega de tierras con el gobierno nacional -tierras que aún conservan, aunque cada vez más presionados por los grandes establecimientos rurales que la rodean- y encararon un complejo proceso de reacomodamiento para ajustarse a pautas aceptables por las autoridades del país, incluyendo la formulación de nuevos rasgos identitarios.

El análisis de otros casos muestra situaciones distintas aunque no menos ricas. Así, las comunidades asentadas en la meseta de Somuncura, en plena Patagonia, habían reorganizado, entre fines del siglo $X I X$ y comienzos del XX, al gunas jefaturas y alcanzado cierta prosperidad aún en las difíciles condiciones ambientales en que se instalaron. En la provincia de Buenos Aires, el trabajo de un equipo de investigación dirigido por Isabel Hernández ha avanzado en el conocimiento de los avatares de la comunidad mapuche de la ciudad de Los Toldos, particularmente en torno al despojo de las tierras que inicialmente se les otorgaron.

Tal es, a grandes rasgos, la situación actual. Los avances futuros dependerán de nosotros, de nuestra capacidad para articular los proyectos individuales en programas más amplios de investigación, la fuerza para propiciar la incorporación de otros investigadores, especialmente jóvenes, en tales programas, el valor y la audacia de no atarnos a presupuestos y de discutir permanentemente nuestras herramientas teóricas y metodológicas, la creatividad necesaria para encontrar los problemas y formular nuevas preguntas. Los retos están; depende de nosotros aceptarlos.

\section{Referencias Bibliográficas}

Para un estado de la cuestión hasta la década de 1990, ver Raúl J. Mandrini, "Indios y fronteras en el área pampeana (siglos XVI-XIX): 
balance y perspectivas" (Anuario IEHS 7. 1992. Tandil, 1993: 59-73) y "Presentación" (en Relaciones inter-étnicas en el sur bonaerense, 1810-1830. Daniel Villar, ed., Bahía Blanca, UNS-IEHS/U NICEN, 1998: 11-18). Más actualizado, "Hacer historia indígena: el desafío a los historiadores" (en Las fronteras hispanocriollas del mundo indígena latinoamericano en los siglos XVIII-XIX. Un estudio comparativo. Raúl J. Mandrini y Carlos D. Paz, eds. Tandil/Bahía Blanca/N euquén, IEHS/CEHIR/U NS, 2003: 15-32). Sobre la discusión de categorías fundamentales, Miguel A. Palermo: "Reflexiones sobre el Ilamado 'complejo ecuestre' en la Argentina" (RU N A. Archivo para las Ciencias del H ombre, XVI. Buenos Aires, ICA/U BA 1986: 157-178), Raúl J. Mandrini y Sara Ortelli 1996: "Repensando los viejos problemas: observaciones sobre la araucanización de las pampas" (RUNA. Archivo para las Ciencias del Hombre. XXII. Buenos Aires, Museo Etnográfico/U BA): 135-150) y "Los "araucanos" en las pampas (c. 1700-1850)" (en Colonización, resistencia y mestizaje en las Américas (siglos XVI-XX). GuiIlaume Boccara ed. Q uito, Ediciones Abya Yala/IFEA, 2002: 237-257; Sara Ortelli "La 'araucanización' de las pampas: ¿realidad histórica o construcción de los etnólogos? (A nuario IEHS 11. 1996. Tandil, 1996: 203-225); Lidia R. N acuzzi, Identidades impuestas. Tehuelches, aucas y pampas en el norte de la Patagonia (Buenos Aires, Sociedad Argentina de Antropología, 1998).

Sobre trabajos arqueológicos con interés para los historiadores interesados en el tema, véase, entre otros, Biset, Ana María y Gladys Varela, "El sitio arqueológico de Caepe Malal. Una contribución para el conocimiento de las sociedades indígenas del noroeste neuquino" (Cuadernos de Investigación: Arqueología y etnohistoria de la Patagonia septentrional. María T. Boschín, coordinadora. Tandil, IEHS/U N CPBA, 1991: 18-35); Ferrer, Eduardo A. y Victoria Pedrotta, Los corrales de piedra. Comercio y asentamientos aborígenes en las sierras de Tandil, Azul y Olavarría Tandil, Ediciones Crecer, 2006; Hajduk, Adán y Ana M. Biset, "Principales características del sitio arqueológico 'Caepe Malal I' -valle del río Curi Leuvú- departamento de Chos Malal (provincia de Neuquén). Informe preliminar", en Cuadernos de Investigación: Arqueología y etnohistoria de la Patagonia septentrional. María T. Boschín, coordinadora. Tandil, IEH-S/U NCPBA, 1991: 6-17); M aría del Carmen Langiano, Julio M erlo y Pablo O Imazábal, "Relevamiento de fuertes y fortines, con relación al camino de los indios a Salinas" (en Del mar a los salitrales. Diez mil años de historia pampeana en el umbral del tercer milenio, D. L. Mazzanti, 
M. A. Berón y F. W. O liva, eds. Mar del Plata/Buenos Aires, U niversidad Nacional de Mar del Plata / SAA, 2002: 53-64); Patricia Madrid, "Infraestructura indígena para el mantenimiento y traslado de ganado introducido: el caso del sistema serrano de Pillahuincó, provincia de Buenos Aires" (Boletín del Centro, 3. La Plata, CERPAP, 1991: 65-71); Diana Leonis Mazzanti: "Control del ganado caballar a mediados del siglo XVIII en el territorio indio del sector oriental de las serranías de Tandilia" (en Huellas en la tierra. Indios, agricultores y hacendados en la pampa bonaerense. Raúl Mandrini y Andrea Reguera, eds. Tandil, IEH S/UNCPBA, 1993: 75-89), "Arqueología de un asentamiento araucanizado postconquista en las serranías orientales de Tandilia, pcia. de Buenos Aires" (en Soplando el viento... Actas de las III Jornadas de Arqueología de la Patagonia [San Carlos de Bariloche, 1996]. Neuquén, Universidad Nacional del Cómale, 1999: 451-460), e "Interacción social postconquista en las sierras de Tandilia. El caso de la localidad arqueológica Amalia" (en La región pampeana -su pasado arqueológico-. Carlos J. Gradín y Fernando O liva, eds. s/l, Laborde editores / SAA / CEAR2004: 201-209); Victoria Pedrotta, Las sociedades indígenas del centro de la provincia de Buenos Aires entre los siglos XVI y XIX. Tesis doctoral inédita (La Plata, Facultad de Ciencias Naturales y Museo / U niversidad Nacional de La Plata 2005); Alicia H. Tapia, "Distribución espacial de asentamientos ranqueles en el norte de la provincia de La Pampa (siglos XVIII y XIX)" (en Del mar a los salitrales. Diez mil años de historia pampeana en el umbral del tercer milenio, D. L. Mazzanti, M. A. Berón y F. W. O liva, eds. Mar del Plata/Buenos Aires, Universidad Nacional de Mar del Plata / SAA, 2002: 65-83), y "Relaciones interétnicas y cambio cultural en la frontera al sur del río Cuarto. Perspectiva arqueológica" (en Signos en el tiempo y rastros en la tierra. III Jornadas de Arqueología e Historia de las Regiones Pampeana y Patagónica. Mariano Ramos y Eugenia Néspolo, eds. Luján, U niversidad N acional de Luján, 2003: 284-293).

Sobre la cuestión de la etnicidad y los procesos de etnogénesis, ver G uillaume Boccara, Guerre et ethnogenèse mapuche dans le Chili colonial. L'Invention du Soi (Paris-Montreal, L'Harmattan, 1998) y "Organisation sociale, guerre de captation et ethnogenèse chez les Reche-Mapuche à l'époque coloniale" (L'Homme, 150. París, 1999: 85118); G ary C. Anderson, The Indian Southwest, 1580-1830. Ethnogenesis and Reinvention (Norman, U niversity of O klahoma Press, 1999); Jonathan D. Hill, ed., History, Power and Identity. Ethnogenesis in the Americas, 1492-1992 (lowa City, U niversity of lowa Press, 1996). 
Para un panorama general de los conocimientos sobre los temas referidos a la etapa anterior a la ocupación militar del territorio indígena, véase entre otros, M artha A. Bechis R., Interethnic relations during the Period of $\mathrm{N}$ ation-State formation in Chile and Argentina: from Sovereign to Ethnic (Ann Arbor, MI, University Microfilms International, 1984); Leonardo León Solís, Maloqueros y conchavadores en A raucanía y las Pampas, 1700-1800 (Temuco, Ediciones U niversidad de la Frontera, 1991); Raúl J. Mandrini, "Pedir con vuelta. ¿Reciprocidad diferida o mecanismo de poder?" (Antropológicas, NE, 1. M éxico, IIA/UNAM, 1992: 59-69), “ ¿Sólo de caza y robos vivían los indios? La organización económica de los cacicatos pampeanos del siglo XIX", en Siglo XIX. Revista de Historia. 2a época, no 15 (M éxico, Instituto Mora, 1994: 5-24), "El viaje de la fragata San Antonio en 1745-1746. Reflexiones sobre los procesos políticos operados entre los indígenas pampeano-patagónicos" (Revista Española de Antropología Americana no 30 (Madrid, Universidad Complutense, 2000: 235-263), y "Articulaciones económicas en un espacio fronterizo colonial. Las pampas y la Araucanía a fines del siglo XVIII y comienzos del XIX" (en Historia ambiental de la ganadería en México. Lucina Hernández, comp. Xalapa, Méx., Instituto de Ecología AC., 2001: 48-58); Raúl J. Mandrini y Sara O rtelli, Volver al país de los araucanos (Buenos Aires, Editorial Sudamericana, 1992), Miguel A. Palermo, "La compleja integración hispano-indígena del sur argentino y chileno durante el período colonial" (América Indígena, vol. LI, 1. M éxico, 1991: 153-192); Jorge Pinto Rodríguez, "Redes indígenas y redes capitalistas. La Araucanía y las Pampas en el siglo XIX" (en Los pueblos campesinos de las Americas. Etnicidad, cultura e historia en el siglo XIX. H. Bonilla y A. Guerrero Rincón, editores. Bucaramanga, Universidad Industrial de Santander, 1996); Ratto, Silvia: "La estructura de poder en las tribus amigas de la provincia de Buenos Aires (1830-1850)" (Q uinto Sol. Revista de Historia Regional, Año 1, № 1. Santa Rosa, U niversidad Nacional de La Pampa, 1997: 75-102), y La frontera bonaerense (1810-1828) Espacio de conflicto, negociación y convivencia (La Plata, Archivo Histórico de la Provincia de Buenos Aires, 2003); Gladys Varela y Ana María Biset, "Los Pehuenche en el mercado colonial" (Revista de Historia, 3. Neuquén, Universidad Nacional del Comahue, 1992: 149-157), y: "Entre guerras, alianzas, arreos y caravanas: los indios de Neuquén en la etapa colonial" (en Susana Bandieri y otros, Historia de Neuquén (Buenos Aires, Plus UItra, 1993: 65-106); Julio Esteban Vezub, Valentín Saygüeque y la "Gobernación Indígena de las Manzanas". Poder 
y etnicidad en Patagonia noroccidental (1860-1881). Tesis doctoral inédita (Tandil, Facultad de Ciencias Humanas / U niversidad N acional del Centro de la Provincia de Buenos Aires, 2005); Daniel Villar y Juan F. Jiménez, "Botín, materialización ideológica y guerra en las pampas durante la segunda mitad del siglo XVIII. El caso de Llanketruz" (Revista de Indias, LX, 220. M adrid, CSIC, 2000: 687-707), y "La tempestad de la guerra: conflictos indígenas y circuitos de intercambio. Elementos para una periodización (Araucanía y las pampas, 1780-1840)" (en Las fronteras hispanocriollas del mundo indígena latinoamericano en Ios siglos XVIII-XIX. Un estudio comparativo. Raúl Mandrini y Carlos D. Paz, eds. Tandil/Bahía Blanca/N euquén, IEHS/CEHIR/UNS, 2003: 123-171).

Entre los trabajos recientes realizados sobre el período posterior a la ocupación militar del territorio, pueden verse M aría Elba Argeri, De guerreros a delincuentes. La desarticulación de las jefaturas indígenas y el poder judicial. Norpatagonia, 1880-1930 (Madrid, Consejo Superior de Investigaciones Científicas, 2005); Walter Mario Delrío, M emorias de expropiación. Sometimiento e incorporación indígena en la Patagonia. 1872-1943 (Bernal, U niversidad Nacional de Quilmes, 2005); Débora Finkelstein, "Mecanismos de acceso a la tierra y narraciones de identidad en la Colonia Pastoril Aborigen de Cushamen (Provincia del Chubut)" Cuadernos del Instituto Nacional de Antropología y Pensamiento Latinoamericano, № 19. Buenos Aires, INAPL, 2000-2002: 231-247), y "Miguel Ñancuche Nahuelquir. 'Mudando la piel como los matuastos" (en Vivir entre dos mundos. Las fronteras del sur de la Argentina. Siglos XVIII-XIX. Raúl Mandrini, ed. Buenos Aires, Taurus, 2006: 355-382); Gustavo Fischman e Isabel Hernández, La ley y la tierra. Historia de un despojo en la tribu mapuche de Los Toldos (Buenos Aires, Centro de Estudios Avanzados (UBA) / CEAL, 1990); Enrique H. Mases, Estado y cuestión indígena. El destino final de los indios sometidos en el sur del territorio (1878-1910) (Buenos Aires, Entrepasados/Prometeo libros, 2002). Un interesante análisis, desde la lingüística, en Marisa Malvestitti, "El poblamiento mapuche de la Línea Sur después del aukan. Aspectos históricos y lingüísticos" (Anclajes, VI. 6, Parte 1, 2002: 79-102). 